5 Meade TW, Wilkes HC, Stirling Y, Brennan PJ, Kelleher C, Browne W. Randomized controlled trial of low dose warfarin in the primary prevention of ischaemic heart disease in men at high risk: design and pilot study. Euro Heart J 1988;9:836-43.

6 Meade TW, Roderick PJ, Brennan PJ, Wilkes HC, Kelleher CC Extra-cranial bleeding and other symptoms due to low dose aspirin and low intensity oral anticoagulation. Thromb Haemost 1992;68:1-6.

7 Meade TW, Mellows S, Brozovic M, Miller GJ, Chakrabarti RR, North WRS, et al. Haemostatic function and ischaemic heart disease: principal results of the Northwick Park heart study. Lancet 1986;2:533-7.

8 World Health Organization Regional Office for Europe. Myocardial infarction community registers. Copenhagen: WHO, 1976. (Public Health in Europe, No 5.)

9 Löwel H, Dobson A, Keil U, Herman B, Hobbs MST, Stewart A, et al. Coronary heart disease case fatality in four countries: a community study. Circulation 1993;88:2524-31

10 Alexander JH, Harrington RA, Tuttle RH, Berdan LG, Lincoff AM, Deckers JW, et al. Prior aspirin use predicts worse outcomes in patients with non-ST-elevation acute coronary syndromes. Am J Cardiol 1999;83: $1147-51$
11 Col NF, Yarzebski J, Gore JM, Alpert JS, Goldberg RJ. Does aspirin consumption affect the presentation or severity of acute myocardial infarction? Arch Intern Med 1995;155:1386-9.

12 Garcia-Dorado D, Theroux P, Tornos P, Sambola A, Oliveras J, Santos M, et al. Previous aspirin use may attenuate the severity of the manifestation of acute ischaemic syndromes. Circulation 1995;92:1743-8.

13 Antiplatelet Trialists' Collaboration. Collaborative overview of myocardial infarction and stroke by prolonged antiplatelet therapy in various categories of patients. BMJ 1994;308:81-106.

14 Hansson L, Zanchetti A, Carruthers SG, Dahlof B, Elmfeldt D, Julius S, et al. Effects of intensive blood-pressure lowering and low-dose aspirin in patients with hypertension: principal results of the hypertension optima treatment (HOT) randomised trial. Lancet 1998;351:1755-62.

15 Weil J, Colin-Jones D, Langmam, Lawson D, Logan R, Murphy M, et al. Prophylactic aspirin and risk of peptic ulcer bleeding. BMJ 1995;310: $827-30$

16 Ramsay LE, Williams B, Johnston GD, MacGregor GA, Poston L, et al. British Hypertension Society guidelines for hypertension management 1999: summary. BMJ 1999;319:630-5.

(Accepted 16 March 2000)

\title{
Risk of acquiring Creutzfeldt-Jakob disease from blood transfusions: systematic review of case-control studies
}

\author{
Kumanan Wilson, Catherine Code, Maura N Ricketts
}

\begin{abstract}
Objective To determine the strength of association between history of blood transfusion and development of Creutzfeldt-Jakob disease. Data sources English and non-English language articles published from January 1966 to January 1999 were retrieved using a keyword search of Medline and Embase. These were supplemented by handsearching key journals and searching bibliographies of reviews. Study selection Two independent reviewers selected the relevant abstracts and articles. Articles were chosen that reported the results of case-control studies trying to identify rates of prior blood transfusion in patients with Creutzfeldt-Jakob disease and in controls.
\end{abstract}

Data extraction Odds ratios and information on study quality were extracted from the selected articles by two independent reviewers.

Data synthesis Five studies containing data on 2479 patients were included. Three of the five studies used medical or neurological patients as controls, the other two used population controls. Odds ratios for developing Creutzfeldt-Jakob disease from blood transfusion ranged from 0.54 to 0.89 . Four of the five studies had confidence intervals that crossed 1.0. The combined odds ratio was $0.70(95 \%$ confidence interval 0.54 to 0.89 ).

Conclusions Case-control studies do not suggest a risk of developing Creutzfeldt-Jakob disease from blood transfusion. Rather, a trend seems to exist towards a lower frequency of previous blood transfusion in patients with Creutzfeldt-Jakob disease than in controls. However, it is important to be aware of these studies' methodological limitations-primarily the choice of control population and reliability of recall of transfusion status.

\section{Introduction}

The possibility of iatrogenic transmission of Creutzfeldt-Jakob disease via blood transfusion has recently attracted increased attention owing to the known transmissibility of hepatitis $\mathrm{C}$ and HIV via blood. ${ }^{1}$ Owing to the rarity of Creutzfeldt-Jakob disease and the potentially long latency period case-control studies are well suited to determine if an association exists between Creutzfeldt-Jakob disease and blood transfusion. We have conducted a systematic review of the evidence of blood transmission of sporadic Creutzfeldt-Jakob disease from case-control studies. Studies of variant Creutzfeldt-Jakob disease were not included in the review.

\section{Methods}

We conducted a search of English and non-English language articles in the Medline database from January 1966 to January 1999. We also searched the Embase database from 1988 to 1999 . We supplemented this search by handsearching key journals and searching bibliographies of reviews.

Two authors independently evaluated the abstracts and the retrieved articles and also extracted data. Articles selected for the systematic review had to meet two criteria. They had to have studied patients with Creutzfeldt-Jakob disease and controls, and they had to have determined the rate of blood transfusion in patients with Creutzfeldt-Jakob disease and controls. Odds ratios were calculated using the Meta-analyst program. $^{2}$

\section{Results}

Study selection and characteristics

The Medline and Embase searches yielded 302 citations, including 14 case-control studies. Of these studies, four met the inclusion criteria. ${ }^{3-6} \mathrm{~A}$ fifth study released after the searches were conducted was later identified and included in this analysis. ${ }^{7}$ Thus five studies, involving 2479 patients, were included in the final analysis. Two studies were conducted in the United Kingdom, ${ }^{45}$ one in Japan, ${ }^{3}$ one in Europe, ${ }^{6}$ and one in Australia.
Division of General Internal Medicine, University of Ottawa, Ottawa, Ontario, Canada Kumanan Wilson assistant professor

Department of Medicine, Ottawa Hospital-Civic Campus, 1053 Carling Avenue, Ottawa, Ontario K1Y 4E9 Catherine Code resident in internal medicine

Room L410, Department of Surveillance and Response, World Health

Organization, Avenue Appia, CH-1211, Geneva 27, Switzerland

Maura N Ricketts medical adviser on human and animal health

Correspondence to: K Wilson, Civic Parkdale Clinic 737 Parkdale Avenue, Suite 414, Ottawa, Ontario, Canada K1Y 1J8 kwilson@lri.ca

BMJ 2000;321:17-9

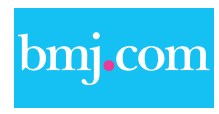

Further methods material can be found on the BMJ'S website 
Table 1 Study characteristics

\begin{tabular}{|c|c|c|c|c|c|}
\hline & Kondo et al, $1982^{3}$ & $\begin{array}{l}\text { Harries-Jones et al, } \\
1988^{4}\end{array}$ & Esmonde et al, $1993^{5}$ & Van Dujin et al, $1998^{6}$ & Collins et al, $1999^{7}$ \\
\hline $\begin{array}{l}\text { Primary goal to determine the odds } \\
\text { of receiving transfusion }\end{array}$ & No & No & Yes & No & No \\
\hline Criteria for diagnosing CJD & Masters & Masters & Masters & Masters & Masters \\
\hline Source of controls & Population & Hospital & Hospital & Hospital & Population \\
\hline Strategy for identifying cases & Request for notification & $\begin{array}{l}\text { Request for notification } \\
\text { or death certificates }\end{array}$ & CJD registers & $\begin{array}{l}\text { Request for notification or } \\
\text { death certificates }\end{array}$ & $\begin{array}{l}\text { CJD registers, death certificates, } \\
\text { hospital coding }\end{array}$ \\
\hline Assessment of transfusion history & Surrogate report & Surrogate report & Surrogate report & Surrogate report & Surrogate report \\
\hline $\begin{array}{l}\text { Interval between transfusion and } \\
\text { disease development }\end{array}$ & Five years & Not assessed & 174 months (mean) & Not assessed & Not assessed \\
\hline Dose-response relation & Not assessed & Not assessed & Not assessed & Not assessed & $\begin{array}{l}\text { Decreased odds ratio with } \\
\text { increased number of transfusions } \\
\text { (not significant) }\end{array}$ \\
\hline
\end{tabular}

$\mathrm{CJD}=$ Creutzfeldt-Jakob disease

Only one of the studies had a primary goal to determine the odds of receiving a blood transfusion. ${ }^{5}$ The other four studies were looking more broadly for risk factors for Creutzfeldt-Jakob disease. All studies used the Masters criteria to define cases of CreutzfeldtJakob disease and included definite and probable cases. $^{8}$ All studies described a clear strategy for identifying cases. Two studies selected population controls $^{3}{ }^{7}$; the rest identified medical or neurological patients as controls. All studies used age and sex matched controls, and all relied on surrogate reporting of transfusion history, most frequently from a close relative (table 1 ).

\section{Risk of Creutzfeldt-Jakob disease from blood transfusion}

All studies showed a trend towards a lower risk of Creutzfeldt-Jakob disease in patients who had received a blood transfusion, with one study showing this association to be significant. ${ }^{6}$ Odds ratios ranged from 0.54 to 0.89 (table 2). A combined odds ratio using a DerSimonion-Laird random effects model reached significance (odds ratio 0.70 (95\% confidence interval 0.54 to 0.89$)$ ). A statistical test for heterogeneity was negative $(\mathrm{P}=0.62){ }^{9}$ The combined odds ratio should be interpreted with caution owing to theoretical concerns relating to combining data from observational studies. ${ }^{10}$

Two studies provided information on the interval between transfusion and development of CreutzfeldtJakob disease. One study only identified cases in which transfusions had been received in the five years up to the development of Creutzfeldt-Jakob disease. ${ }^{3}$ One study reported a mean interval of 174 months between transfusion and development of the disease. ${ }^{5}$ Only one study examined for a possible dose-response relation,

Table 2 History of blood transfusion, with odds ratios for developing Creutzfeldt-Jakob disease if having received blood transfusion

\begin{tabular}{|c|c|c|c|c|c|c|}
\hline \multirow[b]{2}{*}{ Study (year) } & \multirow[b]{2}{*}{ Subjects } & \multicolumn{2}{|c|}{ Cases } & \multicolumn{2}{|c|}{ Controls } & \multirow[b]{2}{*}{ Odds ratio $(95 \% \mathrm{Cl})$} \\
\hline & & Yes & No & Yes & No & \\
\hline Kondo et al, $1982^{3}$ & 163 & 1 & 59 & 3 & 100 & 0.56 (0.06 to 5.56$)$ \\
\hline $\begin{array}{l}\text { Harries-Jones et al, } \\
1988^{4}\end{array}$ & 276 & 15 & 77 & 37 & 147 & 0.77 (0.40 to 1.50$)$ \\
\hline Esmonde et al, $1993^{5}$ & 402 & 21 & 134 & 46 & 201 & 0.68 (0.39 to 1.20$)$ \\
\hline Van Dujin et al, $1998^{6}$ & 719 & 38 & 303 & 71 & 307 & $0.54(0.35 \text { to } 0.83)^{\star}$ \\
\hline Collins et al, $1999^{7}$ & 919 & 27 & 118 & 158 & 616 & $0.89(0.57$ to 1.40$) \dagger$ \\
\hline
\end{tabular}

${ }^{*}$ Results of matched analyses: 0.56 (0.37 to 0.97$)$.

tResults of matched analyses: 0.89 (0.57 to 1.40$)$. and it found a progressively lower odds ratio with increasing number of transfusions, although significance was never reached. ${ }^{7}$

\section{Discussion}

This systematic review does not support an association between blood transfusion and development of sporadic Creutzfeldt-Jakob disease. A trend seems to exist, however, towards a protective effect of transfusion. An excluded study that did not provide raw data reported an odds ratio of 0.6 for having received a blood transfusion, which was consistent with the findings of this review. ${ }^{11}$

\section{Limitations}

Although case-control studies are well suited for determining associations in conditions that have low frequency and long latency periods, they are susceptible to bias. The major source of bias contributing towards the apparent beneficial effect of blood transfusion involves selection of controls in the primary studies. Three of the five studies used medical patients or neurological patients as controls. ${ }^{4-6}$ Presumably, these individuals would be at higher risk than the average population of having received a blood transfusion.

Bias may also occur as a result of inaccurate ascertainment of transfusion status. Studies have found that $25-40 \%$ of transfusion recipients do not recall having received transfusions. ${ }^{12}$ The necessary reliance on reporting from surrogates, usually relatives, also contributes to inaccurate ascertainment. However, for recall bias to produce a decreased association between Creutzfeldt-Jakob disease and blood transfusions, family members of patients with Creutzfeldt-Jakob disease would have to be less likely to recall transfusion history than family members of controls.

Three of the five primary studies did not provide the results of matched analyses. ${ }^{3-5}$ This is an important methodological limitation and illustrates the need for caution if using data from case-control studies. The failure to use matched analyses generally produces a bias towards the null effect. ${ }^{13}$

\section{Other studies}

Despite the limitations of the primary studies it seems unlikely, from the results presented in this systematic review, that blood transfusions contribute towards 
development of sporadic Creutzfeldt-Jakob disease. Evidence from other sources also seems to support the lack of an association. Results from animal studies have been equivocal, although a study from the US National Institute of Health concluded that the human blood could not transmit Creutzfeldt-Jakob disease to animals. ${ }^{14}$ This may, however, be more a function of the species barrier than of infectivity. A study of preserved brain samples of 25 haemophilic patients-who have high exposure to blood transfusions and potentially higher exposure to blood infected with the agent responsible for CreutzfeldtJakob disease-found no evidence of the disease. ${ }^{15}$ "Look back" studies have not identified any cases of Creutzfeldt-Jakob disease developing in recipients who received blood from a donor in whom the disease was later diagnosed. ${ }^{16}{ }^{17}$ No extended controlled cohort studies have been conducted to determine if blood transfusion recipients are at increased risk of Creutzfeldt-Jakob disease.

\section{Generalisability}

The results of this systematic review pertain to the transmissibility of sporadic Creutzfeldt-Jakob disease and should not be generalised to variant CreutzfeldtJakob disease. Variant Creutzfeldt-Jakob disease differs from the sporadic form in several respects: a shorter latency period, presentation with behavioural symptoms, and longer duration of disease before death. In particular, the lymphoreticular system seems to be a site for collection of the prion protein in variant Creutzfeldt-Jakob disease, with large amounts found in the appendices and tonsils of affected individuals. This affinity for the lymphoreticular system may increase the likelihood of variant Creutzfeldt-Jakob disease being transmitted via blood. ${ }^{18}$ One case-control study examining the risk of transmission of variant Creutzfeldt-Jakob disease from blood transfusions did not find any association (UK Creutzfeldt-Jakob Disease Surveillance Unit, www.cjd.ed.ac.uk/rep98.html (accessed 1 September 1999)).

\section{Conclusion}

This study illustrates some of the difficulties in attempting to determine causal relations in the area of infectivity of blood products. Despite the methodological advantages of case-control studies in studying rare diseases with long latency periods, potential exists for significant levels of bias that can produce apparently spurious results. It is important to recognise these limitations when attempting to address the question of infectivity of variant Creutzfeldt-Jakob disease via blood transfusion.

We acknowledge Drs Andreas Laupacis and Paul Hebert for the advice they provided in preparing the manuscript; Keith O'Rourke for statistical advice; Ilona MacLaren for help in translation of foreign language articles; and Jessie McGowan for help in designing and carrying out the Medline and Embase search strategy.

Contributors: KW designed the study, selected the included papers, extracted data, conducted the statistical analysis, and prepared the manuscript. He will also act as guarantor for the paper. CC selected the included papers, extracted data, and reviewed the final manuscript. MNR provided background information on Creutzfeldt-Jakob disease and indicated potential sources of bias in the primary studies. She also reviewed the final manuscript.

\section{What is already known on this topic}

Potential blood transmission of sporadic Creutzfeldt-Jakob disease has been a concern in several countries

Current evidence suggests that no link exists between blood transfusion and development of sporadic Creutzfeldt-Jakob disease

\section{What this study adds}

This systematic review summarises the results from five case-control studies examining the risk of developing sporadic Creutzfeldt-Jakob disease from blood transfusions

No study shows an association

Patients with Creutzfeldt-Jakob disease were less likely to have received blood transfusions than controls, suggesting a protective effect of transfusions; this apparently spurious result is probably the consequence of methodological limitations of the primary studies

The study draws attention to the importance of having well designed case-control studies when trying to assess the risk of developing variant Creutzfeldt-Jakob disease from blood transfusion

Funding: This study has been funded by a grant from the Medical Council of Canada.

Competing interests: None declared.

1 Krever H. Commission of inquiry on the blood system in Canada. Final report. Canadian Government Publishing: Ottawa, Canada, 1997.

2 Lau J. Meta-analyst program (0.988). Boston, MA: New England Medical Center, 1990.

3 Kondo K, Kuroiwa Y. A case-control study of Creutzfeldt-Jakob disease: association with physical injuries. Ann Neurol 1982;11:377-81.

4 Harries-Jones R, Knight R, Will RG, Cousens S, Smith PG, Mathews WB. Creutzfeldt-Jakob disease in England and Wales, 1980-1984: a case-control study of potential risk factors. J Neurol Neurosurg Psychiatry $1988 ; 51: 1113-9$

5 Esmonde TFG, Will RG, Slattery JM, Knight R, Harries-Jones R, de Silva $\mathrm{R}$, et al. Creutzfeldt-Jakob disease and blood transfusion. Lance 1993;341:205-7.

6 Van Dujin CM, Delasnerie-Laupretre N, Masullo C, Zerr I, deSilva R, Wientjens DPWM, et al. Case-control study of risk factors of CreutzfeldtJakob disease in Europe during 1993-1995. Lancet 1998;351:1081-5.

7 Collins S, Law MG, Fletcher A, Boyd A, Kaldor J, Masters CL. Surgical Collins S, Law MG, Fletcher A, Boyd A, Kaldor J, Masters CL. Surgical
treatment and risk of sporadic Creutzfeldt-Jakob disease: a case-control study. Lancet 1999;353:693-7.

8 Masters CL, Harris JO, Gajdusek DC, Gibbs CJ Jr, Bernoulli C, Asher DM. Creutzfeldt-Jakob disease: patterns of worldwide occurrence and the significance of familial and sporadic clustering. Ann Neurol 1979;5:177-88.

9 Julian JA. Summary odds ratios for $2 \times 2 \times$ k tables. Version 1.0. Hamilton, Ontario: McMaster University, 1993.

10 Egger M, Schneider M, Smith GD. Spurious precision? Meta-analysis of observational studies. BMJ 1998;316:140-4.

11 Davanipour Z, Alter M, Sobel E, Asher D, Gajdusek DC. Creutzfeldt-Jakob disease: possible medical risk factors. Neurology 1985;35:1483-6.

12 Ricketts MN, Cashman NR, Stratton EE, ElSaadany. Is Creutzfeldt-Jakob disease transmitted in blood? Emerg Infect Dis 1997;3:155-63.

13 Rothman KJ, Greenland S. Matching. In: Rothman KJ, Grennland S, eds. Modern epidemiology. Philadelphia, PA: Lippincott-Raven, 1998:147-61.

14 Brown P, Gibbs CJ Jr, Rodgers-Johnson P, Asher DM, Sulima MP, Bacote A, et al. Human spongiform encephalopathy: the NIH series of 300 cases of experimentally transmitted disease. Ann Neurol 1994;44:513-5.

15 Evatt B, Austin H, Barnhart E, Schonberger L, Sharer L, Jones R, et al. Surveillance for Creutzfeldt-Jakob disease among persons with hemophilia. Transfusion 1998;38:817-20.

16 Heye N, Hensen S, Muller N. Creutzfeldt-Jakob disease and blood transfusion. Lancet 1994;343:298-9.

17 Operalski EA, Mosley JW. Pooled plasma derivatives and CreutzfeldtJakob disease. Lancet 1995;346:1224.

18 Hill AF, Zeidler M, Ironside J, Collinge J. Diagnosis of new variant Creutzfeldt-Jakob disease by tonsil biopsy. Lancet 1997;349:99-100.

(Accepted 28 March 2000) 